\title{
Higher-Order Thinking Learning Outcomes through the Problem-Based Learning Model
}

\author{
Hari Sugiharto Setyaedhi \\ Departement of Education Technology \\ Universitas Negeri Surabaya \\ Surabaya, Indonesia \\ harisetyaedhi@unesa.ac.id
}

\begin{abstract}
A weakness of the lecture-based learning method in universities is that students lack the ability to critically solve problems when learning materials that require problem-solving. Students are not given the opportunity to develop their critical thinking. The purpose of this research is to train university students to think critically when coping with the challenges of their daily lives. Students therefore need to be exposed to problem-based learning activities with a view to build their Higher-Order Thinking Skills (HOTS). The research applies a classroom action research method that involves 44 university students in total as participants. Data is collected through observation, tests, discussions and evaluation, each of which is conducted for Cycles 1 and 2. In Cycle 1, a mean score of 59, while in Cycle 2 an average score of 83 . It can be concluded from this research that the problem-based learning approach can indeed improve the higher-order thinking skills of university students.
\end{abstract}

Keywords-higher-order thinking skills; problem-based learning

\section{INTRODUCTION}

From observations conducted by the researcher, it was found that university students lack higher-order thinking skills. This is partly due to a conventional learning approach that relies on the lecture method, and the problems given to students to solve tend to focus on the rote memorization of theories that does not require analysis, therefore less need for critical thinking when solving problems found in learning materials. For lecturers who are already accustomed to teaching the conventional way of standing before the class, it would be relatively hard for them to adjust to a new teaching style [1].

Pursuant to Government Regulation No. 19/2006, the learning process of an educational unit should be done in such a way that is interactive, inspiring, fun, challenging, and motivating for university students to actively participate in, and where ample space is provided for initiatives, creativity and independence according to the student's talent, interest as well as physical and psychological development. To this end, a learning design or plan should be developed through the right strategy. In an effort to build Higher Order Thinking Skills (HOTS), first-semester students are given the ProblemBased Learning (PBL) model.

Problem-based learning differs from the usual classroombased discussion method as it emphasizes on an instructional model that trains and develops the ability to solve problems that are rooted in the authentic problems that a student faces in a real-life situation. Problem solving is essentially the responsibility of the student as an individual and not as part of a group. Students therefore can effectively solve their own problems without having to depend on others. This encourages the student to put in his or her best effort in learning, working and taking responsibility towards achieving predetermined goals. The Learning Plan as mandated in the Government Regulation refers to a learning plan that is anchored in a problem-based learning strategy as people's lives are never far from social problems.

Problem-Based Learning (PBL) is an instructional model designed to help students acquire key knowledge that will enable them to solve problems, learn independently and develop teamwork skills. One of the advantages of PBL is that it helps maintain a strong connection between theory and practice [2]. This is because knowledge always builds up during practice sessions. Within the PBL context, a student's learning process begins with a practice foundation and the theory grows from the practice [1].

Students can learn independently or within a group by working on problems given through the PBL method [3]. PBL is designed on the premise that we are able to solve the multiple problems that we face in our daily lives [4].

So far, the learning activity tends to be teacher-centered that the student has lack participation in the learning process. As the result, the students acquired the material passively and they are lacking of problems solving skill. This would decrease the students' motivation intrinsically. In order to overcome this issue, an effective learning model that allows students to actively involve in the teaching learning process is necessary. One of the learning models is PBL [5].

The ultimate goal of PBL is to assist learners to build their intrinsic motivation. Intrinsic motivation increases when the learner is motivated by his or her interest and feels challenged and satisfied when working on an assignment. Students will become more motivated when they appreciate what they have learnt. They also become increasingly motivated when they believe that learning outcomes are under their control.

Higher-Order Thinking does not simply involve memorization, but also a variety of cognitive processes, such as assessment, generating ideas, exploring consequences, considering available options, monitoring progress and others 
[6]. Educators view HOTS as high-order thinking that occurs when students acquire new knowledge and store it in his or her memory, which is then connected, organized and evaluated to achieve a specific purpose [7]. Bloom's taxonomy illustrates higher-order thinking skills as shown in Figure 1. To develop higher-order thinking skills, the lecturer needs to engage with students through learning activities and assignments that go beyond simple comprehension at the second level, moving further to reach the level of application, analysis, synthesis and evaluation. This is in line with the notion that higher-order thinking skills cover the ability to think that requires more than the simple remembrance or memorization of information.

It should be noted that critical problems cannot be solved simply through the application of acquired knowledge, but should also involve the individual in the process of critical and creative thinking in order to make the most of the acquired knowledge. Based on Bloom's taxonomy, HOT includes the ability to analyze, evaluate and create [8].

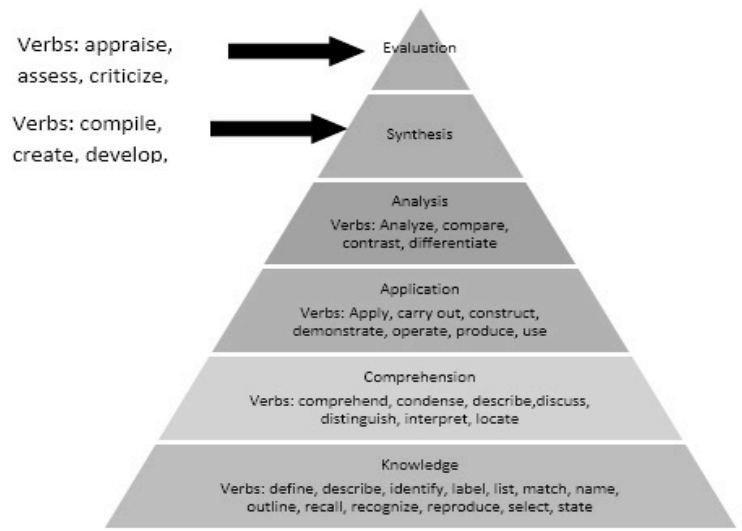

Fig. 1. Higher-Order Thinking Bloom's Taxonomy

This can be explained as follows:

- Analyze is an activity that involves a number of actions such as analyzing, contrasting and differentiating, sorting and organizing according to a specific set of criteria, then a correlation is established and its meaning interpreted.

- Evaluate is an action that involves an assessment based on certain criteria and standards. This ability covers two key categories: the ability to examine and criticize.

- Create is the process of making a new product that does not previously exist. This ability covers three subcategories: the ability to generate, plan and produce

The ability to think at high levels is an essential element in the teaching and learning process. A person's thinking skills can influence his or her learning ability, pace and effectiveness. It is therefore important to pay attention to a student's thinking ability in the learning process. A university student who is trained to think shows positive impact in his or her academic development.

\section{METHOD}

The study adopts the classroom action research method (CAR) [9]. The data collection technique covers observation, tests, and evaluation of discussions in every cycle. The research is conducted at the Faculty of Educational Sciences, Department of Educational Technology, under the Cognitive Development course. Participants are 44 first-semester students.

The research is carried out in two cycles with the following procedure: (1) Pre-CAR that involves Preliminary Reflection, Observation and Pre-Cycle Action; 2) Cycle I implementation that consists of the planning stage, followed by the implementation of action, observation and reflection; 3) Cycle 2 implementation with the same stages as the previous cycle. The classroom action research process flow is provided in Figure 2.

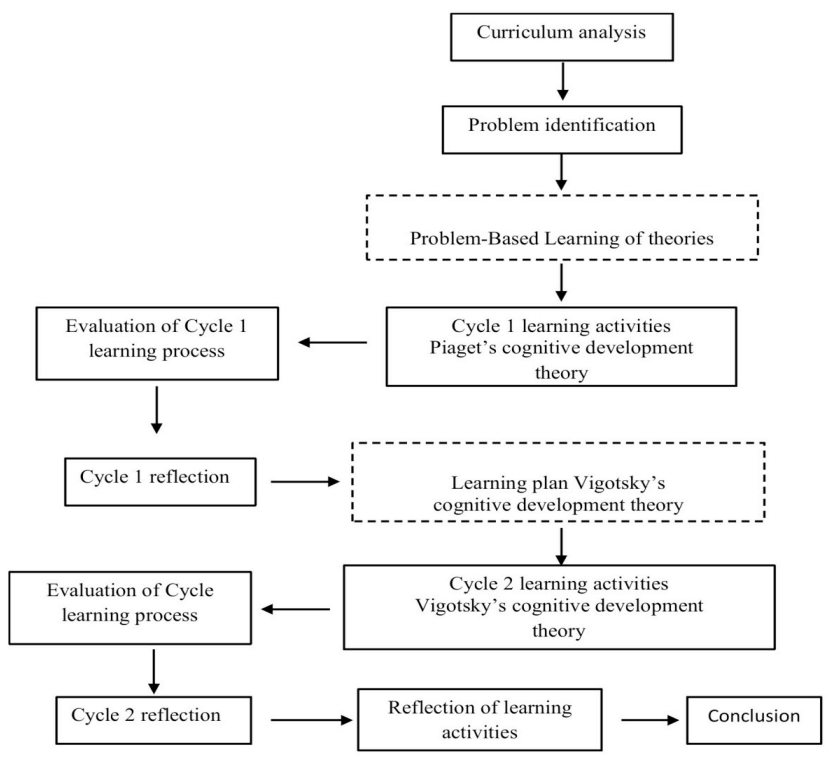

Fig. 2. Classroom Action Research Flowchart

The research instruments include the following:

1. Student Worksheet (SWS)

Through problem-based learning, students are expected to solve the problems given, which requires critical analysis in providing the answers.

2. Written Test

A written test is used for understanding a student's mastery of concepts and his or her learning outcomes relating to the individual's higher-order thinking skills that encompass analyzing (C4), evaluating (C5), and concluding (C6) concepts that the student has come across during the problem-based learning process. The type of test used is an essay examination that is given during group discussions and final evaluations in Cycles 1 and 2.

Data Processing and Analysis Techniques

Data is processed according to the type of data and instruments used. 
1. Student Worksheet (SWS)

A student worksheet (SWS) is a worksheet on a student's ability to master learning materials on cognitive development in the PBL process for the concepts taught to the students. SWS data is processed through the following stages:

1) Identify the completed SWS

2) Give a score for each point on the worksheet

3) Add the scores earned by each group

4) Create a bar chart based on the mean SWS score for each cycle of every group.

2. Written Test

The end of every cycle always concludes with a cycle evaluation test. In this research, data is obtained on the evaluation of Cycles I and II. The available data is processed through the following stages:

1) Identify the completed SWS

2) Give a score for each indicator in the SWS according to the answer key provided

3) Add the scores of each student

4) Calculate the student's mean written test score

\section{Student Observation Data}

Observation data available in the observation sheet is used to learn about a student's activities during the learning process (Cycles 1 and 2). Data is processed through the following stages:

1) Identify the observation sheet filled out by the observer.

2) The results of activity observation in a group are calculated by tallying the activities that take place, and the mean value is calculated for each activity.:

\section{RESULTS AND DISCUSSION}

\section{A. Discussion Group Analysis for Cycles 1 and 2}

The SWS of each discussion group completed by the student is then graded for each cycle (Cycles 1 and 2) to measure the mastery of cognitive development theories through the problem-based learning model. The research lecturer gives every group questions based on a problem, expecting them to analyze the problem through critical thinking. A comparison of group discussions in Cycles 1 and 2 is presented in Figure 3 .

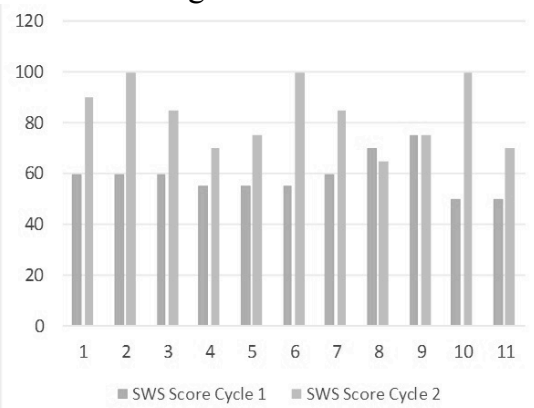

Fig. 3. Analysis of Discussion Group for Cycles 1 and 2
Based on Figure 3 that compares the scores of discussion groups for each cycle, the outcomes are clearly observable as evidenced in the increase of the mean score of discussion groups for their mastery of cognitive development concepts. The comparative total scores and mean scores of discussion groups have significantly increased. In Cycle 1, total score reached 650 with a mean score of 59, whereas in Cycle 2 total value rose to 915 with a mean score of 83 . This demonstrates that all groups showed tremendous improvements. The data above showed that in Cycle 2 university students have begun to have a good grasp of the problem-based learning model for enhancing higher-order thinking skills.

\section{B. Analysis of Final Evaluation Results for Cycles 1 and 2}

From the overall results of the final evaluation it was found that the mastery of learning materials on cognitive development on average has increased. Students' mastery of concepts in Cycle 1 is presented in Table 1, and Cycle 2 in Figure 4.

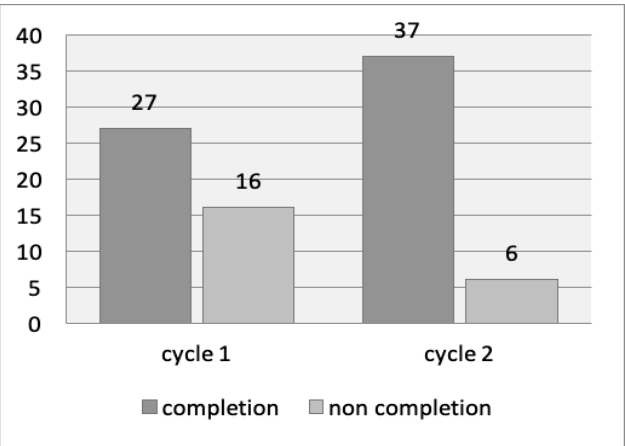

Fig. 4. Analysis of Final Results for Cycles 1 and 2

A comparison of the final evaluation for Cycles 1 and 2 as illustrated in Figure 4 reveals a marked increase in terms of completion. In the final evaluation for Cycle 1, 27 students achieved completion, while for Cycle 2 the number rose to 37 students.

PBL has been effective in increasing HOTS because problem-based learning uses real life contexts throughout the learning process, allowing students to better understand and imagine what they will be learning [5].

Another study has revealed that the higher-order thinking skills of students in an experimental classroom that applies a scientific approach in the problem-based learning model that is integrated with the inculcation of $4 \mathrm{C}$ skills are higher than students in a controlled classroom who are learning through a scientific approach [10].

Research has shown that the adoption of the PBL model can help develop the higher-order thinking skills of students. This is supported by data on the higher-order thinking activities of students that showed improvements from Cycle 1 to Cycle 2 with regard to the ability to analyze, evaluate and create [11]. 


\section{CONCLUSION}

From the research on Problem Based Learning model, it is concluded that Problem Based Learning model is effective to improve High Order Thinking Skill. It is proven from the improvement on average score of discussion from Cycle I to Cycle II. The average score of students' final evaluation in Cycle 2 is higher than cycle 1 . Therefore, Problem based learning model is proven to improve HOTS learning outcomes among university students.

\section{REFERENCES}

[1] W. Hillman, "Learning How to Learn: Problem Based Learning.," Aust. J. Teach. Educ., 2003.

[2] E. De Graaff and A. Kolmos, "Characteristics of Problem-Based Learning," Int. J. Eng. Educ., 2003.

[3] A. B. Da Silva, A. C. K. de A. Bispo, D. G. Rodriguez, and F. I. F. Vasquez, "Problem-based learning: A proposal for structuring PBL and its implications for learning among students in an undergraduate management degree program," Rev. Gestão, 2018.

[4] N. T. M. Tam, "Using Problem-Based Learning to Promote Students' Use Of Higher-Order Thinking Skills And Facilitate Their Learning," VNU J. Foreign Stud., 2018.

[5] M. Asad, K. Iqbal, and M. Sabir, "Effectiveness Of Problem Based Learning As A Strategy To Foster Problem Solving And Critical Reasoning Skills Among Medical Students," J. Ayub Med. Coll. Abbottabad, 2015

[6] S. Wang and H. Wang, "Teaching and Learning Higher-Order Thinking," Int. J. Art Sci., 2014.

[7] Y. Abosalem, "Assessment techniques and students' higher-order thinking skills," in ICSIT 2018 - 9th International Conference on Society and Information Technologies, Proceedings, 2015.

[8] S. Y. Tan and S. H. Halili, "Effective Teaching of Higher-Order Thinking (HOT) in Education," Online J. Distance Educ. e-Learning, 2015 .

[9] S. Kemmis and R. McTaggart, Paticipatory Action Research: Communicative Action and Public Sphere. 2005.

[10] L. Widiawati, S. Joyoatmojo, and Sudiyanto, "Higher Order Thinking Skills as Effect of Problem Based Learning in the 21 st Century Learning," Int. J. Multicult. Multireligious Underst., 2018.

[11] M. Rubiah, "Implementation of Problem Based Learning Model in Concept Learning Mushroom as a Result of Student Learning Improvement Efforts Guidelines for Teachers," J. Educ. Pract., 2016. 